\section{§8. Development of Lithium Vapor Injector for the Boundary Control}

Tsuchiya, H., Hirooka, Y., Ashikawa, N., Masuzaki, S., Nagayama, Y.,

Zushi, H. (Kyushu Univ.)

In the fusion test devices, the transition to improved confinement mode (H-mode) is one of the most important issues for the self-burning plasma. The reduction of the density of the edge plasma is though of as one of the triggers for the $\mathrm{L}-\mathrm{H}$ transition, according to the reports of relation between the edge density and the confinement [1]. To control the recycling at the first wall, the Li coating was attempted in NSTX. Because the coating was performed before the discharge, the coating effect can be limited. If the sufficient $\mathrm{Li}$ vapor is continuously injected to the diverter, there is a possibility that the un-saturated diverter comes true [2]. In this study, the $\mathrm{Li}$-injector, which can inject $\mathrm{Li}$-vapor during the discharge, was developed for Large Helical Device (LHD), which is suitable for the steady state discharge. It is expected that the coating diverter catches the recycling particles efficiently, and leads to the density control.

For the $\mathrm{Li}$ coating of whole area of Helical diverter of LHD, all we need to do is to inject the vapor to the surrounding plasma, which is located in chaotic openmagnetic field line. The Li particles injected to the plasma are charged up, and transported to the diverter along the filed line. From the stand points of the measuring equipment protection and efficient coating, the all $\mathrm{Li}$ particles are desired to charge up. For this, it is critical to know amount of Li beam flux and its profile.

We made the prototype of the Li vapor injector to check the mechanical issue and principle verification. The nozzle size is important to inject the large amount $\mathrm{Li}$ vapor. Because the vapor pressure increases logarithmically with the temperature, the injector is desired to get 650 degree at least. The flux is $10^{20} \mathrm{Li}$ atoms $/ \mathrm{sec} / \mathrm{cm}^{2}$ at 650 degree. So the nozzle size is $10 \mathrm{~cm}^{2}$ is required. In this study, the $50 \mathrm{~mm} \Phi$ nozzle $\left(19 \mathrm{~cm}^{2}\right)$ is selected. The picture of the prototype is shown in fig.1. The container is made of stainless. The stick Heater $(250 \mathrm{~V}-1000 \mathrm{~W})$ is used.

We carried out the experiment in the cylindrical vacuum chamber which is named LIGHT-1 (Lithium Injection Gettering of Hydrogen and its Transport exps.). The beam shape, located $50 \mathrm{~cm}$ distance from the nozzle end, follows the prediction of simulation based on Monte-Carlo method for the most part. The full width at half maximum (FWHM) of experimental result is $25 \%$ larger than that of the prediction (Fig.2.a). The amount of inspersion is about $1 \%$ of the value expected by the saturated vapor pressure (Fig.2 b). Pressure converted form the experiment result is shown in Fig.3. According to the XPS analysis, significant lithium oxide (Li2O) is detected from the target sample. This result may indicate that the most Li particles travel as oxide. Fig.3 shows also the saturated vapor pressure lines of $\mathrm{Li}$ and $\mathrm{Li} 2 \mathrm{O}$. If flying particles are consisted of $\mathrm{Li}$ and $\mathrm{Li} 2 \mathrm{O}$, the ratio $(\mathrm{Li} /(\mathrm{Li} 2 \mathrm{O}+\mathrm{Li}))$ is supposed $1.2 \%$. There is the feasible assumption that the oxide lithium is made before vacuuming the chamber. When the pure-lithium ingot is exposed to the air, the surface of the ingot easily gets oxidized. In this experiment, the exposure time was $30 \mathrm{~min}$ at least. There is a strong possibility that the surface gets fully oxidized. However the interior portion of the ingot is still pure-lithium, because the oxidized surface shields it from the air. And it is considered that the oxidized surface like a shell remains in the vapor injector, and it would prevent the vaporization of pure-lithium. As a result, the observed flux might become lower than simulation. With some shock, the shell would be broken down and this problem would resolve.

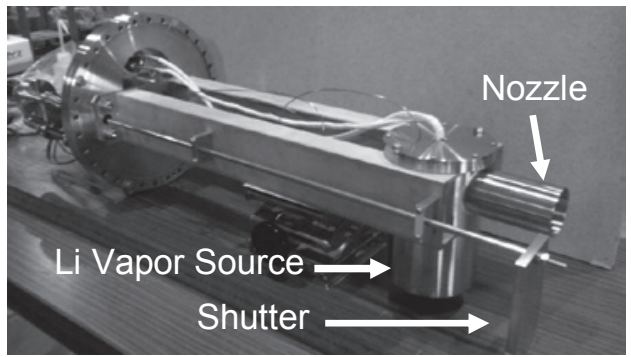

Fig. 1. The picture of the prototype

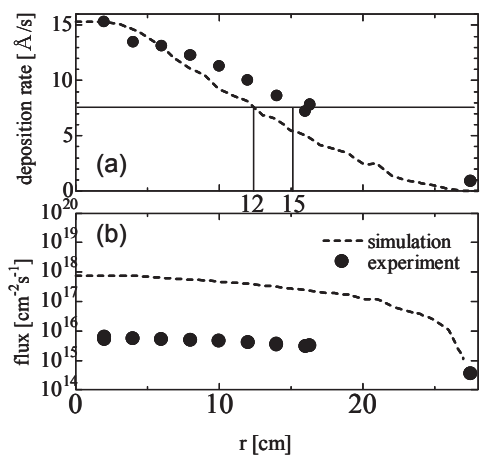

Fig.2 Radial beam profiles of (a) deposition rate and (b) flux. (a) the simulation line is normalized by the data at $\mathrm{r}=2 \mathrm{~cm}$.

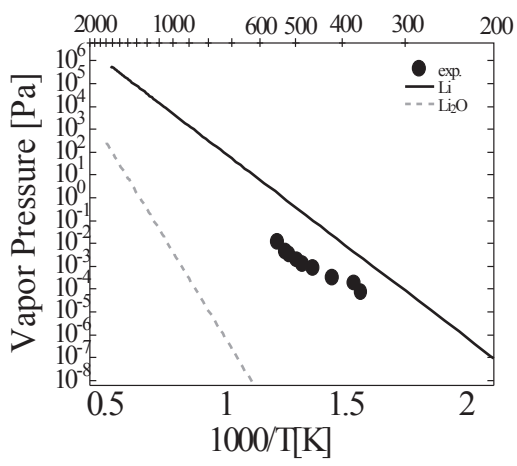

Fig.3 Reconstructed experimental data on vapor pressure curve of pure-lithium and lithium oxide.

[1] N. Ohyabu et al. Phys. Rev. Lett. 97(2006)055002.

[2]H.W. Kugel et al. J. Nucl Materals 363-365 (2007) 791-796

[3] Y. Hirooka et al. Nucl. Fusion 46 (2006) S56-S61. 